\title{
Agriculture and GDP Causality Nexus in Morocco: Empirical Evidence from a VAR Approach
}

\author{
Ouahiba Elalaoui ${ }^{1,}$, , Aziz Fadlaoui ${ }^{2}$, Nassreddine Maatala ${ }^{1}$, Abdelouafi Ibrahimy ${ }^{3}$ \\ ${ }^{1}$ Department of Human Sciences, Hassan II Institute of Agronomy \& Veterinary Medicine, Rabat, Morocco \\ ${ }^{2}$ Rural Economics and Sociology Department, National Institute of Agricultural Research, Meknes, Morocco \\ ${ }^{3}$ Department of Rural Economy, National School of Agriculture, Meknes, Morocco
}

Email address:

ouahiba.elalaoui@gmail.com (O. Elalaoui)

${ }^{*}$ Corresponding author

\section{To cite this article:}

Ouahiba Elalaoui, Aziz Fadlaoui, Nassreddine Maatala, Abdelouafi Ibrahimy. Agriculture and GDP Causality Nexus in Morocco: Empirical Evidence from a VAR Approach. International Journal of Agricultural Economics. Vol. 6, No. 4, 2021, pp. 198-207. doi: $10.11648 /$ j.ijae.20210604.17

Received: June 21, 2021; Accepted: July 5, 2021; Published: August 7, 2021

\begin{abstract}
The agricultural sector continues to be the backbone of the Moroccan's economy, employing $38 \%$ of the active working population and contributing to $13 \%$ of Gross Domestic Product (GDP). However, Moroccan agriculture is subject to multiple constraints, including volatility due to climatic conditions which continue to condition the economic performance of the country as a whole, despite the decrease in the share of agriculture in the sectoral composition. The main objective of this study is to econometrically explore the causality nexus between agriculture and GDP in Morocco, especially since the sector has benefited from new development strategies. Using Moroccan time series over the period 1980 to 2017, the paper employed the Granger causality based on the vector autoregressive model (VAR) in a dynamic multivariate framework, using five macroeconomic variables: GDP per capita, agricultural GDP, investment rate, money supply, and trade openness. The empirical results from the analysis detect the presence of bidirectional Granger causality between agriculture and GDP, implying a feedback relationship, and some unidirectional causal relationships involving the other macroeconomic variables used in the VAR model. The findings have important policy implications for the government to establish effective agricultural strategies, in particular with the inauguration of the new agricultural strategy «Green Generation» in 2020.
\end{abstract}

Keywords: Agriculture, GDP, VAR, Granger Causality

\section{Introduction}

Agriculture is a crucial sector of the Moroccan economy. It contributes to the economic activity of nearly $13 \%$ and employment of $38 \%$ of the active working population, and plays a vital role in the country's food security and poverty reduction in the rural areas where it provides $74 \%$ of total employment [1]. The sector has received renewed interest from political decision-makers and economic actors, materialized mainly by reforms and new development strategies, namely: The Green Moroccan Plan in 2008 and Green Generation in 2020. Thanks to the particular dynamic stimulated by the Green Moroccan Plan launched in 2008 over 12 years and through the mobilization of 104 billion
Dirhams ${ }^{1}$ of private and public investments [2], the agricultural GDP recorded a substantial increase, marked by an average annual growth rate of 5,2\% between 2008 and $2017\left(\mathrm{HCP}^{2}, 2020\right)$. However, despite the decrease in the share of agricultural value added in the sectoral composition from $23.44 \%$ in 1965 to $11.38 \%$ in 2019 (FAOSTAT $^{3}, 2020$ ), the country's economic performance remains intimately linked to the agricultural sector, which is highly dependent on climatic hazards, in particular the drought. Actors always raise the relationship between the agricultural sector and economic activity. Besides, agriculture has been erected as an

\footnotetext{
1 Dirham is the Moroccan currency.

2Authors' calculation based on statistics from the High Commission for Planning of Morocco.

3 Statistics of food and agriculture organization of the united nations
} 
engine of economic growth and an effective tool in the fight against rural poverty. However, few studies have empirically examined the agriculture-GDP nexus in Morocco to verify the role attributed to the agricultural sector. Assessment of the relationship between agriculture and economic growth is of particular importance for policymakers. In fact, the sensitivity of economic activity to agriculture highlights the interest to be accorded to any inappropriate agricultural policy change whose impact will be heavy on the country's economy. Internationally, the empirical literature on the agriculture-GDP nexus is widely discussed and presents divergent results about the causality direction between the two variables [3-6]. This work attempts to fill gaps in factual knowledge of the subject at the national context. The main purpose is to examine the causality direction between agriculture and GDP in Morocco using the Granger causality in a multivariate vector autoregressive model (VAR). The remainder of this paper is structured as follows. Section 2 discusses the existing literature on the nexus between agriculture and GDP. Section 3 reports the used data and the econometric model mobilized. Section 4 analyzes and discusses the obtained results. Finally, the conclusion and policy implications are reported in section 5 .

\section{Literature Review}

\subsection{Empirical Studies}

The role of the agricultural sector has been widely debated in the economic development field [7-13]. The agricultural sector plays a significant role in several developing countries through its contribution to national GDP, job creation, food security, and foreign currency inflows. On the other hand, the upstream and downstream links between agriculture and other sectors of the economy produce a simulation effect of economic growth [14, 15]. Gardner (2003) [16] showed a positive and significant relationship between the growth of agricultural GDP per worker and national GDP per capita for 52 developing countries. The author raised the question about the direction of causality between the two variables. Tiffin and Irz (2006) [17] picked up this analysis using the Granger causality test in the panel data for 85 countries. The main finding of this work is that agricultural value-added is the causal variable in developing countries. However, the direction of causality in developed countries is unclear. A series of empirical studies have been conducted by many authors in different countries to investigate econometrically the role of the agricultural sector and to examine the hypothesis of whether a causal link exists between agriculture and GDP [3-6, 18-20]. Because of the progress accumulated in the econometric analysis, almost all of the studies are based on time series by following an appropriate technique, which is determined mainly by the statistical properties of the variables. Table 1 summarizes the main information on previous studies concerning the AgricultureGDP nexus.

Table 1. Synthesis of some empirical studies.

\begin{tabular}{|c|c|c|c|c|c|}
\hline Reference & Region & Period & Variables & Methodology & Main findings \\
\hline [3] & Indonesia & $1985-2017$ & $\begin{array}{l}\text { Economic growth, agricultural } \\
\text { added value, and industrial } \\
\text { added value. }\end{array}$ & $\begin{array}{l}\text { Vector Error Correction } \\
\text { Model (VECM) }\end{array}$ & $\begin{array}{l}\text { Evidence of a significant impact of agricultural added } \\
\text { value on economic growth only in the short-term; } \\
\text { Presence of a long-term directional causality from the } \\
\text { economic growth on the agricultural added value. }\end{array}$ \\
\hline [4] & Benin & 1961-2014 & $\begin{array}{l}\text { GDP, agricultural output, } \\
\text { industry output and capital. }\end{array}$ & $\begin{array}{l}\text { Vector Error Correction } \\
\text { Model (VECM) }\end{array}$ & $\begin{array}{l}\text { Presence of a long-run relationship between agricultural } \\
\text { output, industrial output, capital, and GDP; } \\
\text { Evidence of a positive impact of agricultural output on } \\
\text { economic growth. }\end{array}$ \\
\hline [5] & Namibia & $1980-2015$ & $\begin{array}{l}\text { Economic growth and } \\
\text { agricultural value added. }\end{array}$ & $\begin{array}{l}\text { Co-integration and } \\
\text { pairwise Granger causality }\end{array}$ & $\begin{array}{l}\text { Evidence of a unidirectional causal relationship running } \\
\text { from agricultural value-added to economic growth. }\end{array}$ \\
\hline [6] & Nigeria & $1981-2015$ & $\begin{array}{l}\text { GDP, value added in the } \\
\text { agricultural sector, government } \\
\text { spending, inflation rate and } \\
\text { population size. }\end{array}$ & $\begin{array}{l}\text { Johansen co-integration } \\
\text { test and error correction } \\
\text { model }\end{array}$ & $\begin{array}{l}\text { Absence of a significant relationship between } \\
\text { agricultural added-value and growth in both the short } \\
\text { and long-run. }\end{array}$ \\
\hline [18] & Thailand & 1961-2009 & $\begin{array}{l}\text { GDP and gross domestic } \\
\text { product of agriculture. }\end{array}$ & $\begin{array}{l}\text { Toda and Yamamoto } \\
\text { approach }\end{array}$ & $\begin{array}{l}\text { Evidence of a long-run causal relationship running from } \\
\text { agriculture to economic growth. }\end{array}$ \\
\hline [19] & $\begin{array}{l}\text { North } \\
\text { Cyprus }\end{array}$ & $1975-2002$ & $\begin{array}{l}\text { Real GDP growth and growth } \\
\text { in agricultural value added. }\end{array}$ & $\begin{array}{l}\text { Granger causality } \\
\text { approach }\end{array}$ & $\begin{array}{l}\text { Presence of a long-run relationship between agriculture } \\
\text { and economic growth; } \\
\text { Presence of bidirectional causality between the variables. }\end{array}$ \\
\hline$[20]$ & Malaysia & $1970-2010$ & GDP and agriculture output. & $\begin{array}{l}\text { Johansen-Juselius co- } \\
\text { integration test and vector } \\
\text { error correction model }\end{array}$ & $\begin{array}{l}\text { Agriculture and economic growth move together in the } \\
\text { long-run; } \\
\text { Absence of causality in the short run; } \\
\text { Presence of a bidirectional causality relationship in the } \\
\text { long-run. }\end{array}$ \\
\hline [21] & Nigeria & $1986-2015$ & $\begin{array}{l}\text { GDP, agricultural output, gross } \\
\text { capital formation, and labor } \\
\text { force. }\end{array}$ & $\begin{array}{l}\text { Autoregressive Distributed } \\
\text { Lag (ARDL) }\end{array}$ & $\begin{array}{l}\text { Evidence of a significant relationship between } \\
\text { agricultural output and economic growth. }\end{array}$ \\
\hline
\end{tabular}




\subsection{An Overview of Agriculture in Morocco}

Agriculture plays a very important socio-economic role in Morocco. It generates $13 \%$ of gross domestic product, with significant fluctuations ranging from $11 \%$ to $18 \%$, depending on the climatic conditions of the agricultural campaign. Figure 1 represents the evolution of the weight of agriculture in the economy. Indeed, the share of agricultural value added (\% GDP) is on a downward trend, marked by a negative average annual growth rate of $-1.33 \%$ between 1965 and 2019 (FAOSTAT, 2020). However, the impact of this sector on the economy remains important because of its spillover effects on other economic sectors. In addition, the sector is a major provider of jobs in Morocco, providing 38\% of jobs, especially in rural areas, which partly explains the economic impact of this sector [1]. Figure 2 shows the interdependence between the agricultural sector and economic activity. The troughs and peaks between the two variables synchronize over time, underscoring the vulnerability of the country's economic activity. The volatility of the agricultural sector is rooted in the heavy dependence of agricultural activity on climatic hazards. The useful agricultural area (UAA) estimated at more than 8 million hectares remains dominated by cereals, which represent $59 \%$ of the UAA [22], as shown in figure $3.90 \%$ of cereal areas are highly dependent on rainfall, which makes Moroccan agriculture more erratic, depending on climatic conditions. Given the importance of agriculture in Morocco, the government launched a sector strategy in 2008 over a 12-year horizon, called the "Green Morocco Plan". This strategy aimed to develop the sector by overcoming the main challenges facing agricultural activity, among others low investment capacity, low participation of the banking system, low level of organization, drought, traditional management of farms, etc. The Green Morocco Plan contained two main pillars. The first has concerned modern agriculture with high added value-oriented towards export. The second pillar has targeted solidarity agriculture to reduce poverty by improving farmer incomes. During this period, the investment has reached significant levels of 104 billion dirhams [2]. Thus, the agricultural sector experienced a particular dynamic, as illustrated in figure 4. Indeed, agricultural value-added has recorded an upward trend marked by an annual growth rate of $5.2 \%$ between 2008 and 2017, much higher than that recorded between 1980 and 2007 estimated at $1.82 \%\left(\mathrm{HCP}, 2020^{4}\right)$.

To capitalize on the achievements of the "Green Morocco Plan" strategy, the ministry of agriculture has launched a new agricultural strategy in 2020, called "Green Generation", which will expire in 2030. The latter is based on two main foundations: the first one gives priority to human capital, mainly through the emergence of an agricultural middle class, able to play a crucial role in the socio-economic balance of rural areas in Morocco. Thus, the strategy consists of the emergence of a new generation of young entrepreneurs and the emergence of a new generation of professional organizations

4 Authors' calculation based on statistics from the High Commission for Planning of Morocco and support mechanisms. The second foundation aims for the sustainability of agricultural development through the consolidation of agricultural sectors, the modernization of distribution chains, the strengthening of quality and innovation, and the consolidation of the resilience of agriculture.

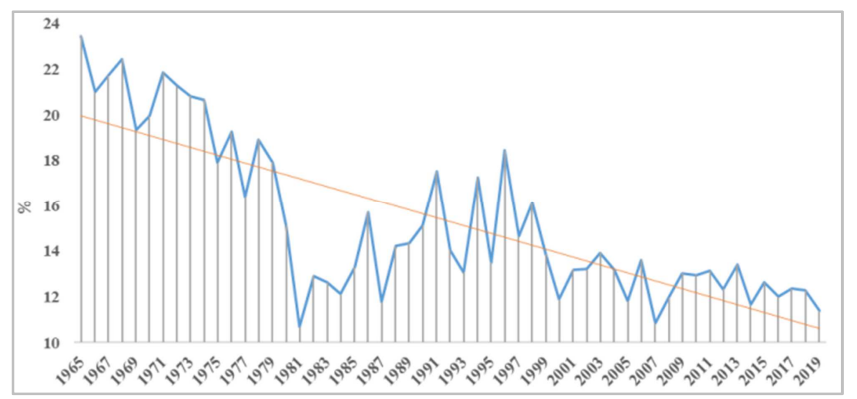

Figure 1. Evolution of the share of agriculture $(\% G D P)$

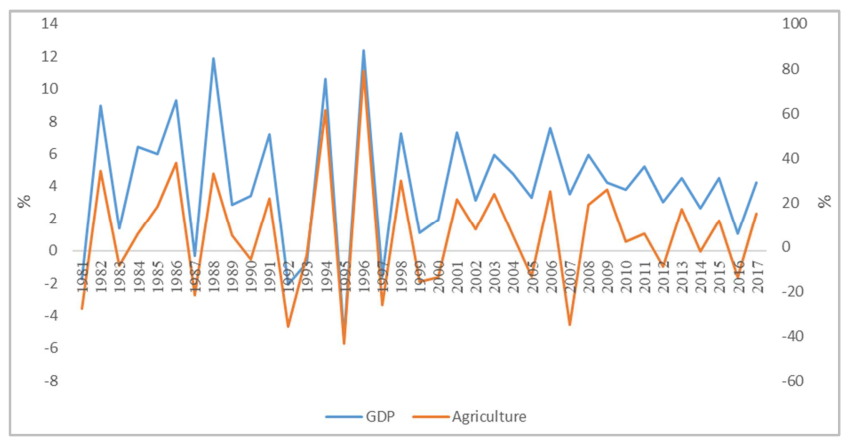

Figure 2. The interdependence between agriculture and GDP.

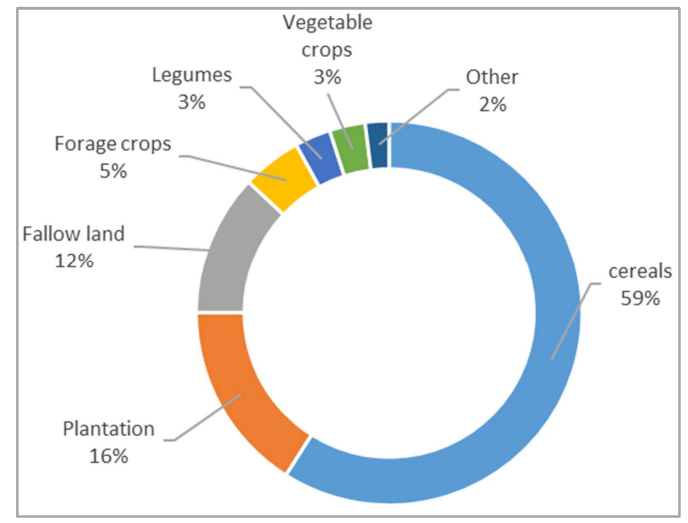

Figure 3. UAA structure in Morocco.

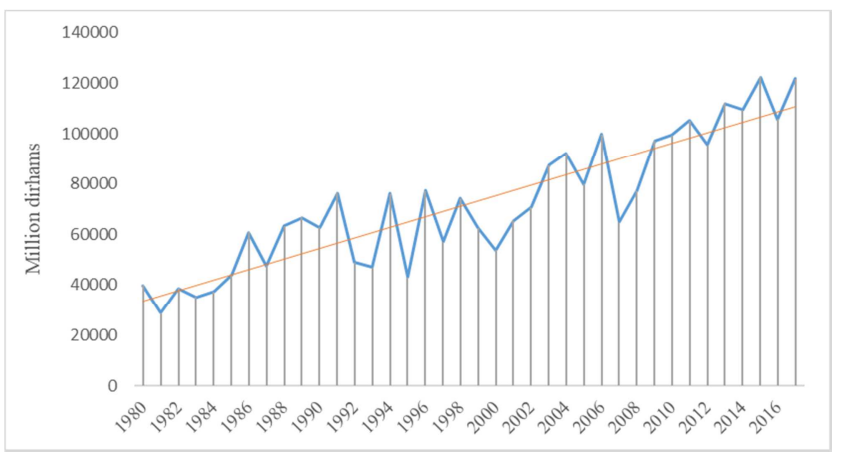

Figure 4. Evolution of agricultural value added in millions of dirhams. 


\section{Research Methodology}

\subsection{Analysis Strategy}

The analytical framework of this study is summarized in figure 5. Indeed, the analysis involves applying an econometric methodology consisting of variables selection, stationarity analysis, lag length selection, vector autoregressive modeling, model validation, and Granger causality testing. It must be pointed out that the choice of the VAR model is guided mainly by the statistical properties of the data, in this case: the degree of integration of the variables and the absence of cointegration relations.

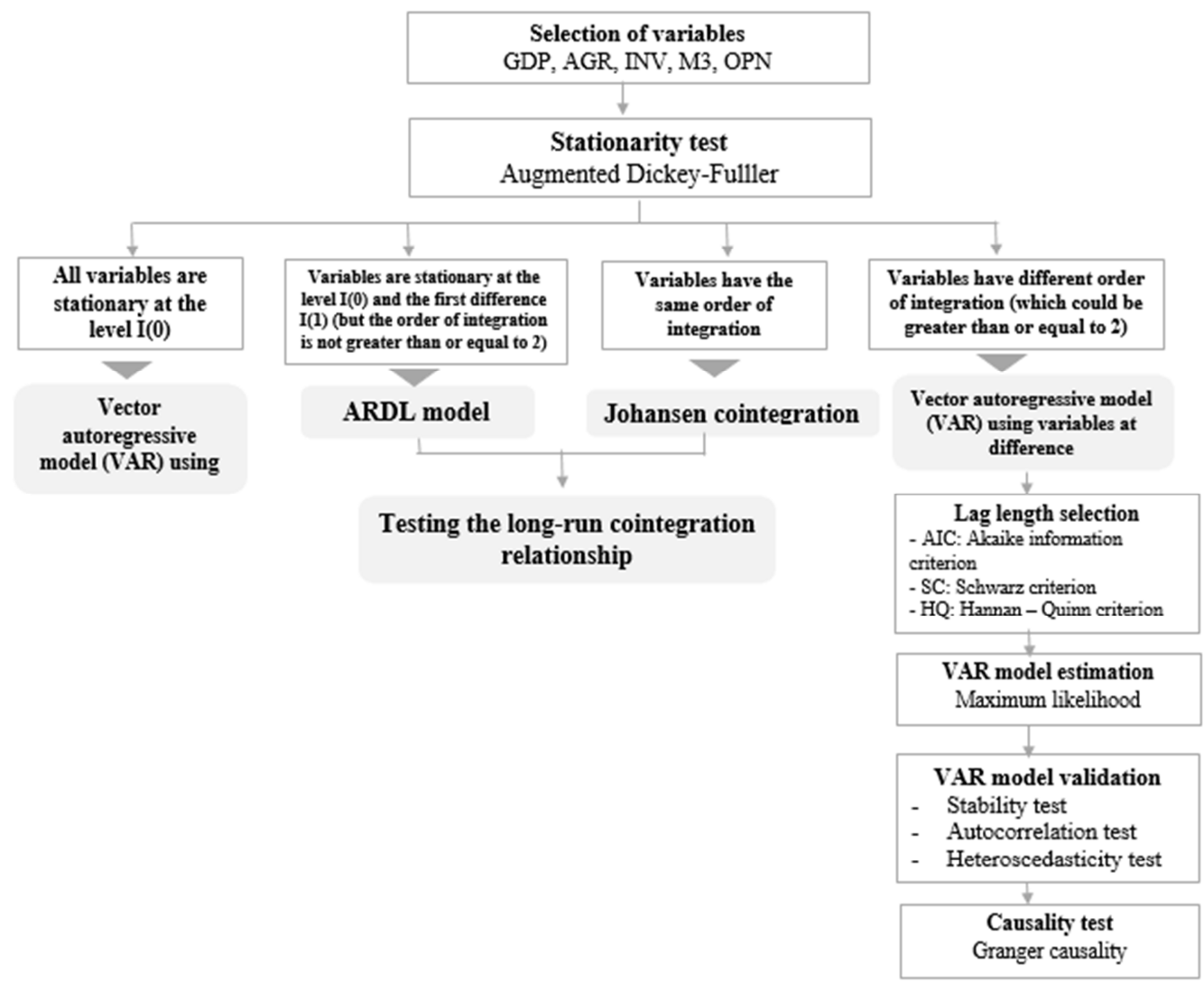

Source: Author's own elaboration

Figure 5. Analysis process of the study.

\subsection{Data}

The VAR model is estimated using annual data over the period 1980-2017. The dataset comes from the directorate of statistics of the High Commission for Planning (HCP) of Morocco. All series are converted into natural logarithms. In order to investigate the agriculture-GDP nexus, other variables such as investment rate [23], money supply [24] and trade openness [25] are also used as control variables to capture the determinants of economic activity and avoid the autocorrelation of errors by omitting important variables. The description of the variables is summarized in table 2 .

Table 2. Data description.

\begin{tabular}{lll}
\hline Variable & Code & Description \\
\hline GDP per capita & GDP & Expressed at chain-linked volume in dirhams MAD (base year: 2007) \\
Agricultural GDP & AGR & Expressed at chain-linked volume in millions of dirhams (base year: 2007) \\
Investment rate & INV & Expressed as a ratio of gross fixed capital formation and GDP (\%) \\
Money supply (M3) & M3 & M3 expressed as a percentage of GDP (\%) \\
Trade openness & OPN & Measured as the sum of exports and imports in GDP (\%) \\
\hline
\end{tabular}

\subsection{Econometric Analysis}

\subsubsection{Stationarity Test}

The first step in the time series analysis is to check the stationarity of the variables under consideration because the data may have unit-roots. The main objective is to avoid spurious relationships between variables and to choose the appropriate model. The econometric literature offers several tests of stationarity, such as Augmented Dickey-Fuller (ADF), Phillips-Perron, KwiatkowskiPhillips-Schmidt-Shin (KPSS), etc. Unit root tests detect the existence of a non-stationary and determine the type of 
non-stationarity and, therefore, the correct method to remove the non-stationarity [26]. Nelson et Plosser (1982) [27] distinguish two classes of non-stationary processes: (i) Trend-Stationary (TS) processes and (ii) DifferenceStationary processes. The first class presents a deterministic non-stationary while the second one contains a stochastic non-stationary indicating the existence of unit-roots. In this study, we selected the most commonly used test, the Augmented Dickey-Fuller (ADF) test.

\subsubsection{Model Specification}

To analyze the relationship between agriculture and GDP, a VAR model incorporating five variables was estimated. The general form of the VAR model with $k$ variables and $p$ lag, (denoted VAR (p)) can be mathematically expressed in equation 1 .

$$
Y_{t}=A_{0}+A_{1} Y_{t-1}+A_{2} Y_{t-2}+\cdots+A_{p} Y_{t-p}+\varepsilon_{t}
$$

Where $Y_{t}$ is a $(k \times 1)$ vector of endogenous variables; $A_{1}, \ldots, A_{p}$ are $(k \times k)$ matrices of lag coefficients, $A_{0}$ is a $(k x 1)$ vector of constants and $\varepsilon_{t}$ is a $(k \times 1)$ white noise innovation process, with $E\left(\varepsilon_{t}\right)=0, E\left(\varepsilon_{t}, \dot{\varepsilon}_{t}\right)=\Sigma_{\varepsilon}$ and $E\left(\varepsilon_{t}, \varepsilon_{s}\right)=0$ (for $t \neq s$ ). Equation 1 can be written using the delay operator $\mathrm{D}$ as follows (Equations 2 and 3 ):

$$
\left(I-A_{1} D-A_{2} D^{2}-\cdots-A_{p} D^{p}\right) Y_{t}=A_{0}+\varepsilon_{t}
$$

Or:

$$
A(D) Y_{t}=A_{0}+\varepsilon_{t}
$$

In the case of this work $(\mathrm{k}=5)$, the components of the VAR model are defined as follows (4):

$$
Y_{t}=\left[\begin{array}{c}
G D P_{t} \\
A G R_{t} \\
M 3_{t} \\
I N V_{t} \\
O P N_{t}
\end{array}\right] A_{0}=\left[\begin{array}{c}
a_{1}^{0} \\
a_{2}^{0} \\
a_{3}^{0} \\
a_{4}^{0} \\
a_{5}^{0}
\end{array}\right] A_{i \neq 0}=\left[\begin{array}{ccccc}
a_{1 i}^{1} & a_{1 i}^{2} & a_{1 i}^{3} & a_{1 i}^{4} & a_{1 i}^{5} \\
a_{2 i}^{1} & a_{2 i}^{2} & a_{2 i}^{3} & a_{2 i}^{4} & a_{2 i}^{5} \\
a_{3 i}^{1} & a_{3 i}^{2} & a_{3 i}^{3} & a_{3 i}^{4} & a_{3 i}^{5} \\
a_{4 i}^{1} & a_{4 i}^{2} & a_{4 i}^{3} & a_{4 i}^{4} & a_{4 i}^{5} \\
a_{5 i}^{1} & a_{5 i}^{2} & a_{5 i}^{3} & a_{5 i}^{4} & a_{5 i}^{5}
\end{array}\right] \varepsilon_{t}=\left[\begin{array}{c}
\varepsilon_{1 t} \\
\varepsilon_{2 t} \\
\varepsilon_{3 t} \\
\varepsilon_{4 t} \\
\varepsilon_{5 t}
\end{array}\right]
$$

It should be noted that $Y_{t}$ depends on the lag of itself and the lag of other endogenous variables in the system. Also, the unknown parameters of the VAR model are estimated using the maximum likelihood method. Thus, the variables introduced into the VAR model must be stationary.

\subsubsection{Lag Length Selection}

Selecting an optimal lag is an important step in the VAR approach. The lag chosen must be sufficient to eliminate the autocorrelation of the errors which affect the estimate. Thus, it should be mentioned that a compromise should be made between the lag selection and the degree of freedom. In this study, three commonly employed information criteria were used to select the optimal lag for the VAR model, namely:

1) Akaike information criterion (AIC (5))

$$
A I C=\frac{-2 l}{T}+\frac{2 n}{T}
$$

2) Schwarz criterion (SC (6)):

$$
S C=\frac{-2 l}{T}+\frac{n \log (T)}{T}
$$

$$
H Q=\frac{-2 l}{T}+\frac{2 n \log (\log (T))}{T}
$$

Where $n$ is the total number of estimated parameters in the VAR, $T$ represents the number of observations. $l$ is the loglikelihood value which is computed assuming a multivariate normal distribution as (8):

$$
l=-\frac{T}{2}\left\{k(1+\log 2 \pi)+\log \left|\widehat{\Sigma_{\varepsilon}}\right|\right\}
$$

The optimal lag $\mathrm{p}$ selected is that which minimizes the aforementioned information criteria for the estimated VAR model. Where $\left|\Sigma_{\varepsilon}\right|$ is the determinant of the variance covariance matrix $\Sigma_{\varepsilon}$.

\subsubsection{VAR Model Validation}

Stability diagnostic

The stability diagnostics examine whether the parameters of the estimated model are stable across various sub-samples of the data. Consider a VAR model with $\mathrm{k}$ variables $y_{t}=$ $\left(y_{1 t}, y_{2 t}, \ldots, y_{k t}\right)$ and delay $p(9)$ :

3) Hannan-Quinn criterion (HQ (7))

$$
y_{t}=A_{1} y_{t-1}+A_{2} y_{t-2}+\cdots \cdot A_{p} y_{t-p}+\varepsilon_{t}
$$

The stability of a VAR can be checked by calculating the root of the following formula (10):

$$
\left(I_{k}-A_{1} L-A_{2} L^{2}-\cdots A_{p} L^{p}\right) y_{t}=A(L) y_{t}
$$

The characteristic polynomial is defined as (11): 


$$
\pi(z)=\left(I_{k}-A_{1} z-A_{2} Z^{2}-\cdots-A_{p} Z^{p}\right)
$$

The roots of $|\pi(z)|=0$ give the information about the stationarity diagnostic of the process. It is important to highlight that the estimated VAR is stable (stationary) if all roots have modulus less than one and lie inside the unit circle. If the VAR is not stable, certain results are not valid.

Autocorrelation diagnostic

The presence of autocorrelation in the residuals implies the omission of important information in the estimated model. The Lagrange Multiplier (LM) has been applied to check the whiteness of the residuals. The LM test is sometimes called Breusch-Godfrey test because it was proposed by Breusch and Godfrey [28]. There are two options for the LM test: the first is for autocorrelation at lag order $\mathrm{h}$ and the second one is for autocorrelation for lags 1 to $h$. The null hypothesis of the two versions of the test is that there is no residual autocorrelation. Its alternative is that the residual autocorrelation exists. The $x^{2}$ distribution was found to be a poor approximation of the actual null distribution of $\lambda_{\mathrm{LM}(\mathrm{h})}$ in many situations. To overcome this problem, there are other versions of statistics, such as LRE-stat and RAO-stat [29, 30].

Heteroscedasticity diagnostic

The White heteroscedasticity test is a common tool for checking the variance stability in VAR models. The null hypothesis of homoscedasticity is tested against the alternative of some form of heteroscedasticity to check the goodness of the estimated model.

\subsubsection{Granger Causality}

Granger causality is a statistical concept of causality that is based on prediction, which is used to test whether one variable is useful in forecasting another variable [31]. In other words, $y_{2 t}$ is said to "Ganger-cause" $y_{1 t}$ if the forecast of $y_{1 t}$ is improved by using the past values of $y_{2 t}$. The null hypothesis that "variable $y_{2 t}$ does not Granger-cause variable $y_{1 t}$ " can be tested by a standard Wald test, granted that the variables are stationary.

In the simple case, consider the bivariate VAR (p) model for which the variables $y_{1 t}$ and $y_{2 t}$ are stationary (12):

$$
\left[\begin{array}{l}
y_{1 t} \\
y_{2 t}
\end{array}\right]=\left[\begin{array}{l}
a_{0} \\
b_{0}
\end{array}\right]+\left[\begin{array}{ll}
a_{1}^{1} & b_{1}^{1} \\
a_{1}^{2} & b_{1}^{2}
\end{array}\right]\left[\begin{array}{l}
y_{1 t-1} \\
Y_{2 t-1}
\end{array}\right]+\left[\begin{array}{ll}
a_{2}^{1} & b_{2}^{1} \\
a_{2}^{2} & b_{2}^{2}
\end{array}\right]\left[\begin{array}{l}
y_{1 t-2} \\
y_{2 t-2}
\end{array}\right]+\cdots+\left[\begin{array}{ll}
a_{p}^{1} & b_{p}^{1} \\
a_{p}^{2} & b_{p}^{2}
\end{array}\right]\left[\begin{array}{l}
y_{1 t-p} \\
y_{2 t-p}
\end{array}\right]+\left[\begin{array}{l}
\varepsilon_{1 t} \\
\varepsilon_{2 t}
\end{array}\right]
$$

The null hypothesis that $y_{2 t}$ does not cause $y_{1 t}$ consists in testing the joint nullity of the parameters (13):

$$
b_{1}^{1}=b_{2}^{1}=\cdots=b_{p}^{1}=0
$$

The null hypothesis that $y_{1 t}$ does not cause $y_{2 t}$ consists in testing the joint nullity of the parameters (14):

$$
a_{1}^{2}=a_{2}^{2}=\cdots=a_{p}^{2}=0
$$

In this work, the Granger causality tests are performed within the framework of the multivariate VAR model, using five variables (which must be stationary ${ }^{5}$ ) and two lags ${ }^{6}$. In order to explore the direction of causality between agriculture and GDP, the Granger causality tests are based on the following VAR (2) model (15):

\begin{tabular}{|c|c|c|c|c|c|c|c|}
\hline \multirow{2}{*}{ Variable $^{7}$} & \multicolumn{2}{|l|}{ Level } & \multicolumn{2}{|c|}{ First difference } & \multicolumn{2}{|c|}{ Second difference } & \multirow{2}{*}{ Remark } \\
\hline & ADF & $p$-value & ADF & $p$-value & ADF & $p$-value & \\
\hline GDP & $2.22^{\mathrm{c}}$ & 0.99 & $-0.91^{\mathrm{c}}$ & 0.32 & $-12.31^{\mathrm{c} * * *}$ & 0.00 & $\mathrm{DS}, \mathrm{I}(2)$ \\
\hline AGR & $-5.89^{a * * *}$ & 0.00 & - & - & - & - & TS \\
\hline INV & $0.16^{\mathrm{c}}$ & 0.73 & $-6.07^{* * *}$ & 0.00 & - & - & DS, I(1) \\
\hline OPN & $1.02^{\mathrm{c}}$ & 0.91 & $-7.71^{\mathrm{c}^{* * *}}$ & 0.00 & - & - & DS, I(1) \\
\hline M3 & $1.93^{\mathrm{c}}$ & 0.98 & $-1.49^{c}$ & 0.13 & $-3,13^{\mathrm{c}^{* * *}}$ & 0.00 & $\mathrm{DS}, \mathrm{I}(2)$ \\
\hline
\end{tabular}

$$
\left[\begin{array}{c}
G D P_{t} \\
A G R_{t} \\
M 3_{t} \\
I N V_{t} \\
O P N_{t}
\end{array}\right]=\left[\begin{array}{l}
a_{1}^{0} \\
a_{2}^{0} \\
a_{3}^{0} \\
a_{4}^{0} \\
a_{5}^{0}
\end{array}\right]+\left[\begin{array}{lllll}
a_{11}^{1} & a_{11}^{2} & a_{11}^{3} & a_{11}^{4} & a_{11}^{5} \\
a_{21}^{1} & a_{21}^{2} & a_{21}^{3} & a_{21}^{4} & a_{21}^{5} \\
a_{31}^{1} & a_{31}^{2} & a_{31}^{3} & a_{31}^{4} & a_{31}^{5} \\
a_{41}^{1} & a_{41}^{2} & a_{41}^{3} & a_{41}^{4} & a_{41}^{5} \\
a_{51}^{1} & a_{51}^{2} & a_{51}^{3} & a_{51}^{4} & a_{51}^{5}
\end{array}\right]\left[\begin{array}{l}
G D P_{t-1} \\
A G R_{t-1} \\
M 3_{t-1} \\
I N V_{t-1} \\
O P N_{t-1}
\end{array}\right]+\left[\begin{array}{lllll}
a_{12}^{1} & a_{12}^{2} & a_{12}^{3} & a_{12}^{4} & a_{12}^{5} \\
a_{22}^{1} & a_{22}^{2} & a_{22}^{3} & a_{22}^{4} & a_{22}^{5} \\
a_{32}^{1} & a_{32}^{2} & a_{32}^{3} & a_{32}^{4} & a_{32}^{5} \\
a_{42}^{1} & a_{42}^{2} & a_{42}^{3} & a_{42}^{4} & a_{42}^{5} \\
a_{52}^{1} & a_{52}^{2} & a_{52}^{3} & a_{52}^{4} & a_{52}^{5}
\end{array}\right]\left[\begin{array}{c}
G D P_{t-2} \\
A G R_{t-2} \\
M 3_{t-2} \\
I N V_{t-2} \\
O P N_{t-2}
\end{array}\right]+\left[\begin{array}{c}
\varepsilon_{1 t} \\
\varepsilon_{2 t} \\
\varepsilon_{3 t} \\
\varepsilon_{4 t} \\
\varepsilon_{5 t}
\end{array}\right]
$$

Table 3. Results of ADF test for stationarity.

a , b and ${ }^{\mathrm{c}}$ represent models with constant and trend, with only constant and without constant and trend, respectively.

\footnotetext{
5 The variables GDP, AGR, INV, M3 and OPN are introduced into the VAR model after elimination of non-stationarity.

6 The lag was selected based on the information criteria. The details are provided in section 4 .

7 The variables tested for stationarity are expressed in natural logarithm.
} 


\section{Results and Discussion}

\subsection{Stationarity Analysis}

The Augmented Dickey-Fuller (ADF) test is used to check the time-series properties of the data. The results are summarized in Table 3. The ADF test confirmed a single unit root in investment rate (INV) and trade openness (OPN) series, a double unit root in GDP per capita (GDP), and money supply (M3) series. A DS process generates all these variables, and the best stationary method, therefore, is to use a differentiation filter to eliminate the stochastic trend. The differentiation number differs according to the number of unit roots detected, corresponding to the integration order. However, the agricultural GDP variable (AGR) is generated by a TS process implying the use of the ordinary least squares regression to remove the deterministic trend. Since the series are integrated of different orders, the Johansen cointegration test to check for possible cointegration between the variables is unsuitable in this case. Thus, the use of the Autoregressive Distributed Lag (ARDL) model is impossible since there are variables with the order of integration greater than one. Therefore, the statistical properties of the selected variables dictated the choice of autoregressive vector modelling. The VAR is valid to use only when there is no cointegration among variables.

\subsection{Lag Length Selection}

Table 4 indicates the suggested lag length based on AIC, $\mathrm{SC}$, and HQ criteria. The criteria AIC and HQ propose two lags, while the criterion SC chooses a single lag. To select the optimal lag, it is advisable to check the robustness of the results using a VAR model with a single lag versus a VAR model with two lags. The residual diagnosis of the VAR (1) and VAR (2) models reveals that the VAR model with lag $=1$ shows the obvious autocorrelation of errors. On the other hand, the properties of the residuals of the VAR model with the inclusion of two lags are satisfactory. Given the above, the VAR model estimated in this study includes two lags.

Table 4. Lag lengh selection criteria

\begin{tabular}{llll}
\hline Lag & AIC & SC & HQ \\
\hline 0 & -12.44064 & -12.21618 & -12.36409 \\
1 & -14.70943 & $-13.36264^{*}$ & -14.25014 \\
2 & $-15.13352^{*}$ & -12.66440 & $-14.29148^{*}$ \\
\hline
\end{tabular}

\subsection{VAR model Validation}

In order to draw reliable and rigorous conclusions about the causal relationships based on the VAR model estimated with two lags, it is first necessary to validate the model.

\subsubsection{Stability Diagnostic}

Figure 6 shows the unit circle of the inverse roots. There are ten roots since the estimated VAR model contains five endogenous variables and two lags. The results reveal that the modulus of all inverse roots is less than 1 and lies inside the unit circle, which is an indication that the VAR satisfies the stability condition.

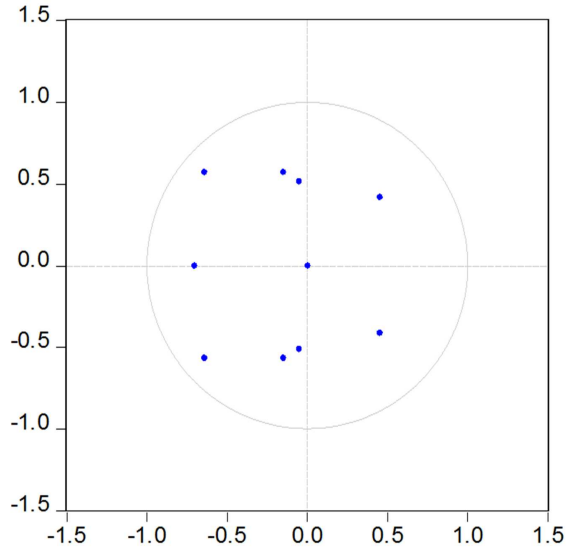

Figure 6. Inverse Roots of AR Characteristic Polynomial.

\subsubsection{Autocorrelation Diagnostic}

Table 5 presents the results of the Breusch-Godfrey Serial Correlation LM Test. Regarding the two null hypotheses, all the probabilities are greater than 0.05 related to the two statistics (LRE stat and Rao F-stat), thus revealing the robustness of the results. From Table 5, the estimated VAR (2) residuals show no evidence of serial correlation for the different lags examined. Consequently, the absence of autocorrelation of the errors indicates that there is no important information that has not been accounted for in the reduced VAR model, which highlights the goodness of fit of the VAR (2) estimated.

Table 5. The results of the serial correlation LM test.

\begin{tabular}{|c|c|c|c|c|c|c|}
\hline \multicolumn{7}{|c|}{ Null Hypothesis: No serial correlation at lag h } \\
\hline Lag & LRE* $^{*}$ stat & Df & Prob. & Rao F-stat & df & Prob. \\
\hline 1 & 27.59373 & 25 & 0.3269 & 1.131747 & $(25,53.5)$ & 0.3435 \\
\hline 2 & 27.29785 & 25 & 0.3412 & 1.116888 & $(25,53.5)$ & 0.3579 \\
\hline 3 & 19.61918 & 25 & 0.7665 & 0.754006 & $(25,53.5)$ & 0.7770 \\
\hline \multicolumn{7}{|c|}{ Null hypothesis: No serial correlation at lags 1 to $\mathrm{h}$} \\
\hline Lag & LRE* $^{*}$ stat & df & Prob. & Rao F-stat & df & Prob. \\
\hline 1 & 27.59373 & 25 & 0.3269 & 1.131747 & $(25,53.5)$ & 0.3435 \\
\hline 2 & 53.37318 & 50 & 0.3459 & 1.049763 & $(50,44.4)$ & 0.4365 \\
\hline 3 & 93.83939 & 75 & 0.0696 & 1.182280 & $(75,23.4)$ & 0.3333 \\
\hline
\end{tabular}

*Edgeworth expansion corrected likelihood ratio statistic.

\subsubsection{Heteroscedasticity Diagnostic}

The results of the White heteroscedasticity test are presented in table 6 . The p-value $(0,2358)$ is larger than 0,05 , corresponding to the significance level. According to this, the null hypothesis ( $H 0$ : Absence of heteroscedasticity) is not rejected and there is no evidence of heteroscedasticity in the residuals of the estimated VAR (2) model. Accordingly, the variance of residuals is constant.

Table 6. VAR Residual Heteroscedasticity Tests.

\begin{tabular}{lll}
\hline Chi-sq & df & Prob. \\
\hline 317.2914 & 300 & 0.2358 \\
\hline
\end{tabular}

\subsection{Granger Causality}

Since the VAR (2) model is stable, the residuals are not 
autocorrelated and their variance is constant, the estimated VAR (2) model is econometrically appropriate to derive results about the direction of causality between the variables examined.

The results of the Granger causality tests for the multivariate framework are given in Table 7. The main information given in table 7 is the probability value. Thus, it should be noted that only significance at a $1 \%$ and $5 \%$ level of significance is considered as supporting the Granger causality test. The causality that are significant at the $1 \%$ and 5\% levels are summarized in Figure 7.

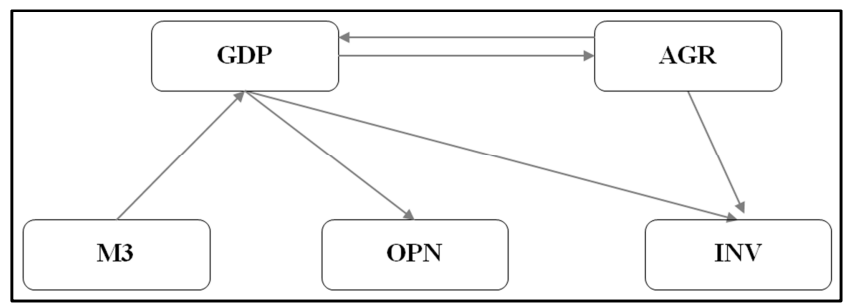

Figure 7. Direction of Granger causality between variables.

The empirical finding for the Granger causality tests of the relationship between agriculture (AGR) and GDP suggests a bidirectional causal linkage. The causality from agriculture to GDP econometrically supports the significant role of agriculture in the Moroccan economy. Consequently, any change in agricultural policy could significantly impact the country's economy. In this regard, the strategies related to the agricultural sector must be well thought out and well developed to avoid any adverse economic impacts. In addition, the second direction of causality directing from GDP to agriculture (retained at a $1 \%$ level of significance.) implies that the agricultural sector can be affected by changes in the economy. The results are consistent with the findings of [19] for North Cyprus and [20] for Malaysia but differ from some authors such as [5] for Namibia and [6] for Nigeria. The direction of causality between agriculture and economy differs from country to country, due to several factors, among others, stage of development, sectoral composition, investment effort in the agriculture sector, etc. There are many channels through which agriculture and the rest of the economy influence each other. Agriculture provides the resources necessary for the development of the non-agricultural sector. It is also an important market for goods produced in other sectors and generates savings that can be used for industrial investments as well as for other sectors of the economy. In addition, foreign exchange accumulated in agriculture through exports of agricultural products can be used to finance imports of capital goods relating to the non-agricultural sector. In Morocco, the export earnings of agricultural products showed an average annual growth of $8.6 \%$ between 2008 and 2018, going from 11.4 billion dirhams to 27.1 billion. Exports of agricultural and agri-food products represented 58.1 billion dirhams in 2018, contributing $13.5 \%$ to exports of goods [32]. On the other hand, the modernization of Moroccan agriculture, in particular within the framework of the agricultural strategy
" The Green Moroccan Plan" supposes the use of new technologies and modern inputs (pesticides, machinery, fertilizers, etc.) produced by the non-agricultural sector. In this way, the agricultural and non-agricultural components influence each other. In Morocco, the upstream linkage ${ }^{8}$ relating to the agricultural sector, measured through the impact of the increase in demand addressed to the agricultural sector on the national economy, increased from a value of 1.34 to 1.41 between the two periods 2000-2007 and 2008-2016. On the other hand, the downstream effect ${ }^{9}$ of the agricultural sectors of the national economy increased from 1.71 to around 1.80 between the same periods [1]. This value is significantly higher than the average for branches of the national economy.

Table 7. Results of Granger causality test.

\begin{tabular}{|c|c|c|c|}
\hline \multicolumn{4}{|c|}{ Dependent variable: GDP } \\
\hline Excluded & Chi-sq & df & Prob. \\
\hline AGR & 14.14510 & 2 & 0.0008 \\
\hline INV & 3.390907 & 2 & 0.1835 \\
\hline M3 & 13.42555 & 2 & 0.0012 \\
\hline OPN & 2.177029 & 2 & 0.3367 \\
\hline All & 39.42250 & 8 & 0.0000 \\
\hline \multicolumn{4}{|c|}{ Dependent variable: AGR } \\
\hline Excluded & Chi-sq & df & Prob. \\
\hline GDP & 16.31126 & 2 & 0.0003 \\
\hline INV & 2.690785 & 2 & 0.2604 \\
\hline M3 & 2.622456 & 2 & 0.2695 \\
\hline OPN & 0.493723 & 2 & 0.7812 \\
\hline All & 17.96770 & 8 & 0.0215 \\
\hline \multicolumn{4}{|c|}{ Dependent variable: INV } \\
\hline Excluded & Chi-sq & df & Prob. \\
\hline GDP & 8.225479 & 2 & 0.0164 \\
\hline AGR & 5.696725 & 2 & 0.0579 \\
\hline M3 & 0.004439 & 2 & 0.9978 \\
\hline OPN & 0.855095 & 2 & 0.6521 \\
\hline All & 19.71338 & 8 & 0.0115 \\
\hline \multicolumn{4}{|c|}{ Dependent variable: M3 } \\
\hline Excluded & Chi-sq & df & Prob. \\
\hline GDP & 1.244299 & 2 & 0.5368 \\
\hline AGR & 5.156763 & 2 & 0.0759 \\
\hline INV & 0.652874 & 2 & 0.7215 \\
\hline OPN & 1.416993 & 2 & 0.4924 \\
\hline All & 16.24477 & 8 & 0.0390 \\
\hline \multicolumn{4}{|c|}{ Dependent variable: OPN } \\
\hline Excluded & Chi-sq & df & Prob. \\
\hline GDP & 6.044725 & 2 & 0.0487 \\
\hline AGR & 1.715784 & 2 & 0.4241 \\
\hline INV & 2.373250 & 2 & 0.3052 \\
\hline M3 & 0.155369 & 2 & 0.9253 \\
\hline All & 8.102268 & 8 & 0.4235 \\
\hline
\end{tabular}

The results show also that there is a unidirectional Granger causality that runs from money supply (M3) to economic growth at a high significance level of $1 \%$. However, there is no causal relationship running from investment rate to GDP and also from trade openness to GDP. The empirical finding

\footnotetext{
${ }^{8}$ The term upstream linkage indicator (backward linkage) is used to indicate the link that exists between a particular branch and the upstream branches from which it purchases its inputs.

${ }^{9}$ The term downstream linkage indicator (forward linkage) is used to describe the link that exists between a particular branch and the downstream branches to which it sells its output.
} 
reveals that there is a unilateral causal relationship from GDP to investment rate as well as from GDP to trade openness. There is also evidence that the agricultural sector causes investment. The empirical explanations of these causalities have different theoretical foundations. Thus, they exceed the objectives of this work.

\section{Conclusion}

The current study sheds light on the causal direction between the agricultural sector and GDP in Morocco by using annual data over the period from 1980 to 2017. Thus, the study determines whether the agricultural sector leads to economic growth in Morocco and/or vice versa. The Granger causality test based on the vector autoregressive model (VAR) was applied. The empirical evidence revealed bidirectional causality, implying feedback within the agriculture-GDP nexus.

This empirical analysis provides important implications for policymakers and economic analysts. First, because of the causality running from agriculture to GDP, the special emphasis is put on the importance of developing wellthought-out and well-established agricultural development strategies to avoid any crowding-out effect on the country's economy. Besides, the results show that GDP affects the agricultural sector. In this sense, any potential benefits of such policies should be exploited to derive the benefits of the boom period. More specifically, policymakers should try to place more emphasis on high value-added agriculture that may yield greater value-added benefits.

In addition, the nexus between agriculture and GDP raises the links between this sector and other sectors of the economy through these spillover effects which remain very apparent during periods of drought. Although the evolution of agriculture in Morocco is greatly impacted by drought periods which become more and more recurrent, the agricultural sector is relatively becoming resilient. The coefficient of variation of the growth rate of agricultural value-added decreased considerably over the period from 1981-1999 to 2000-2017. Strengthening agricultural resilience would increase the positive spillover effects on economic growth and the rest of the economic sectors.

Finally, the coordination between sector strategies should be a priority to ensure further positive effects on economic growth and to ensure a better allocation of resources that remain very limited, in particular with the inauguration of the new agricultural strategy green generation) in 2020 .

\section{References}

[1] Department of Economic Studies and Financial Forecast (DESFF), Ministry of Economy, Finance and Administration Reform, 2019. «Le secteur agricole marocain: Tendances structurelles, enjeux et perspectives de développement».

[2] Ministry of Agriculture, Fisheries, Rural Development, Water and Forests (MAFRDWF), 2020. «Le Maroc vert 2008-2020» achdartleflaha.
[3] Bashir, A., Suhel, Azwardi, Atiyatna, D. P., Hamidi, I. and Adnan, N., 2019. "The Causality Between Agriculture, Industry, and Economic Growth: Evidence from Indonesia» Etikonomi 18 (2): 155-68.

[4] Karimou, S., 2018. «Impact of Agricultural Output on Economic Growth in West Africa: Case of Benin» 30 th International conference of agricultural economists.

[5] Odero, E. E., 2017. " Analyzing the causal relationship between agricultural value addition and economic growth in Namibia» European Journal of Basic and Applied Sciences 4 (2): 9-15.

[6] Asom, S. and Ushahembaljirshar, V., 2016. «Impact of Agriculture Value Added on the Growth of Nigerian Economy» Nigerian Journal of Management Sciences 5 (1): $238-45$.

[7] Hwa, E. C., 1988. «The Contribution of Agriculture to Economic Growth: Some Empirical Evidence» World Development 16 (11): 1329-39.

[8] Johnson, D. G., 1993. «Role of Agriculture in Economic Development Revisited » Agricultural Economics 8 (4): 42134.

[9] Loizou, E., Karelakis, C., Galanopoulos, K. and Mattas, K. 2019. «The Role of Agriculture as a Development Tool for a Regional Economy » Agricultural Systems 173 (March): 482-90.

[10] Timmer, C. P., 1992. «Agriculture and Economic Development Revisited » Agricultural Systems 40 (1-3): 2158 .

[11] Timmer, C. P., 2002. «Chapter 29 Agriculture and economic development» Handbook of Agricultural Economics Volume 2, Part A, 2002, Pages 1487-1546.

[12] Vollrath, T. L., 1994. «The Role of Agriculture and Its Prerequisites in Economic Development. A Vision for Foreign Development Assistance» Food Policy 19 (5): 469-78.

[13] Zhang, Y. and Diao, X., 2020. «The Changing Role of Agriculture with Economic Structural Change - The Case of China » China Economic Review 62.

[14] Degu, A., 2019. «The Causal Linkage Between Agriculture, Industry and Service Sectors in Ethiopian Economy» American Journal of Theoretical and Applied Business 5 (3): 59.

[15] Singariya, M. R. and Kulsresth, S., 2018. «An Empirical Study of Inter-Sectoral Linkages and Economic Growth in India» Euro-Asian Journal of Economics and Finance volume 6, Issue 1 Pages: 1-11.

[16] Gardner, B. L., 2003. «Causes of Rural Economic Development» Working Papers 28559, University of Maryland, Department of Agricultural and Resource Economics.

[17] Tiffin, R. and Irz, X., 2006. «Is Agriculture the Engine of Growth? » Agricultural Economics 35 (1): 79-89.

[18] Jatuporn, C., Chien, L. H., Sukprasert, P. and Thaipakdee, S., 2011. «Does A Long-Run Relationship Exist between Agriculture and Economic Growth in Thailand?» International Journal of Economics and Finance 3 (3).

[19] Katircioglu, S. T., 2006. «Causality between Agriculture and Economic Growth in a Small Nation under Political Isolation: A Case from North Cypru » International Journal of Social Economics 33 (4): 331-43. 
[20] Matahir, H. and Tuyon, J., 2013. «The Dynamic Synergies between Agriculture Output and Economic Growth in Malaysia» International Journal of Economics and Finance 5 (4).

[21] Kehind, O. H. and Agnes, E. O., 2017. «Impact of Agricultural Output Volatility on Economic Growth in Nigeria: Egarch Analysis» IOSR Journal of Agriculture and Veterinary Science 10 (01): 04-10.

[22] Ministry of Agriculture, Fisheries, Rural Development, Water and Forests (MAFRDWF), 2019. «Agriculture en chiffres 2018».

[23] Mehanna, R. A., 2003. "The Temporal Causality Between Investment And Growth In Developing Economies." Journal of Business And Economics Research Volume 1, Number 3.

[24] Dingela, S. and Khobai, H. 2017. «Dynamic Impact of Money Supply on Economic Growth in South Africa. An ARDL Approach» Nelson Mandela University (NMU), MPRA Paper No. 82539.

[25] Gries, T. and Redlin, M., 2012. «Trade Openness and Economic Growth: A Panel Causality Analysis» University of Paderborn, Germany.
[26] Bourbonnais, R., 2015. «Econométrie, Cours et Exercices Corrigés» Edition 9, Dunod.

[27] Nelson, C. R., and Plosser, C. I., 1982. «Trends and random walks in macroeconmic time series some evidence and implications» Journal of Monetary Economics 10 (I 982) 139-162.

[28] Lütkepohl, H., 2006. «New Introduction To Multiple Time Series Analysis» 2006th ed. Springer.

[29] Doornik, J. A., 1996. «Testing Vector Error Autocorrelation and Heteroscedasticity». Nuffield College, Oxford OX1 1NF, UK.

[30] Edgerton, D. and Shukur, G., 1999. «Testing Autocorrelation in a System Perspective Testing Autocorrelation» Econometric Reviews 18 (4): 343-86.

[31] Granger, C. W. J., 1969. «Investigating Causal Relations by Econometric Models and Cross-Spectral Methods» Essays in Econometrics vol II: Collected Papers of Clive W. J. Granger 37 (3): 31-47.

[32] High Commission for Planning (HCP) of Morocco, 2019. «Quelles perspectives pour la dépendance alimentaire du Maroc à l'horizon de 2025?» Les Brefs du Plan, $\mathrm{N}^{\circ} 12 \cdot 26$ décembre 2019. 